\title{
Phthalate Metabolites in Amniotic Fluid and Maternal Urine Samples
}

\author{
Giovanna Tranfo ${ }^{*}$, Enrico Paci ${ }^{1}$, Daniela Pigini' ${ }^{1}$, Rossana Claudia Bonanni' \\ Silvia Capanna', Caterina De Carolis ${ }^{2}$, Sergio Iavicoli ${ }^{1}$ \\ ${ }^{1}$ INAIL Research, Monteporzio Catone, Italy \\ ${ }^{2}$ Gynaecology and Obstetrics II, Azienda Ospedaliera San Giovanni-Addolorata, Rome, Italy \\ Email: "g.tranfo@inail.it
}

Received 3 September 2014; revised 28 September 2014; accepted 24 October 2014

Copyright (C) 2014 by authors and Scientific Research Publishing Inc.

This work is licensed under the Creative Commons Attribution International License (CC BY). http://creativecommons.org/licenses/by/4.0/

(c) (i) Open Access

\begin{abstract}
The objective of this study was to determine the concentrations of the metabolites of four selected phthalates, widely used industrial chemicals which possess endocrine-disrupting properties, in samples of amniotic fluid and maternal urine collected in the same day, in order to verify if the latter can be considered a measure of the fetal exposure. The quantitative determination of the metabolites was carried out by HPLC-MS/MS with isotopic dilution from 70 pregnant volunteers. Detectable concentrations of phthalates metabolites were found in amniotic fluids. As phthalate monoesters are excreted in the urine conjugated with glucuronic acid, an enzymatic hydrolysis is carried out before analysis. Amniotic fluids were tested with and without hydrolysis and only the free phthalate metabolites, not conjugated with glucuronic acid, were found. The concentration of metabolites after enzymatic hydrolysis in maternal urine is not correlated to those of amniotic fluids, but the free form concentrations are. These results suggest that only the free forms can cross the placenta. A significant number of mothers showed urine phthalate monoesters concentrations higher than non-pregnant women.
\end{abstract}

\section{Keywords}

Chemical Exposure, Amniotic Fluid, Urine, Phthalate Metabolite, Glucuronic Acid

\section{Introduction}

Human exposure to chemical agents is considered to be a significant risk factor to public health.

\footnotetext{
${ }^{*}$ Corresponding author.

These authors contributed equally to this work.
} 
Its extent can be assessed through the monitoring of dose and effect indicators on all available biological matrices, from the traditional ones such as blood, urine and exhaled air, to innovative ones such as saliva, the exhaled breath condensate and keratin matrices as hair and nails [1].

The performing of routine amniocentesis on pregnant women between the 14th and the 23rd week of gestation has made available a new matrix, the amniotic fluid, which allows to study prenatal exposure to xenobiotics. Fetuses are in fact exposed to environmental contaminants and their metabolites, as small molecules, are able to cross the placental barrier [2]. The amniotic fluid is a pool of recirculating fetal urine, and therefore it contains traces of the xenobiotics to which the mother is exposed and of their metabolites.

There is a limited number of scientific papers that explore this theme, all published after 1998; the substances investigated are endocrine disruptors such as chlorinated organic compounds, phytoestrogens [3], polychlorobiphenyls PCBs [4] [5], polyphenols [6], the metabolites of some phthalates [7]-[10], nicotine and its metabolite cotinine [11], medicinals and drugs. The average number of samples analyzed is less than 100 . The amniotic fluid samples are specimens that are generally released after the birth of the baby, so it is often not always possible to correlate the levels of xenobiotics determined with those of maternal biological fluids, and sometimes not even with personal information on the pregnant women.

Phthalates, the diesters of phthalic acid (1,2-benzenedicarboxylic acid), are a class of man-made synthetic chemicals with ubiquitous human exposures because of their extensive use since the 1930s. Environmental phthalates act as endocrine disruptors, with potential detrimental health effects [12]. High concentrations have been reported in household dust and indoor air, and phthalates are found in a wide variety of common consumer products. High molecular weight phthalates, such as di(2-ethylhexyl)phthalate (DEHP), are commonly used as plasticizers in building materials, vinyl flooring and in numerous PVC products including clothing (footwear, raincoats), food packaging, and medical devices, whereas low molecular weight phthalates, such as diethyl phthalate (DEP) and dibutyl phthalate (DBP), are used as solvents in cosmetics, insecticides, and pharmaceuticals. The ubiquitous use of phthalates results in human exposure from food, dermal absorption [13], inhalation and parenteral use of medical devices [14]. Recent studies focus on the effects of fetal exposure to phthalates on the male reproductive system showing that DEHP exerts complex and broad disruptive effects on the endocrine system and metabolism [15].

According to the European Directive 79/769/CEE and its following modifications the use of six phthalate diesters is regulated only for what concerns the content in toys and other children products: $D E H P, D B P$, Benzyl Butyl Phthalate (BBP), Diisononyl Phthalate (DiNP), Diisodecyl Phthalate (DiDP) and Dioctyl Phthalate $(D N O P)$.

Urinary metabolite levels are more frequently measured than the parent compounds because the risk of accidental contamination of samples during collection, storage and analysis is greatly reduced [16].

Mother's urinary phthalate metabolite concentrations were associated with infants' concentrations for six phthalate metabolites: monobenzyl phthalate, monoethyl phthalate, monoisobutyl phthalate, and three metabolites of di(2-ethylhexyl) phthalate: mono(2-ethylhexyl) phthalate, mono(2-ethyl-5-hydroxy-hexyl) phthalate, and mono(2ethyl-5-oxo-hexyl) phthalate; however correlation coefficients were generally low but increased with decreasing age of infant [17].

A statistically significant linear correlation was found for the DiNP monoester metabolite (MiNP) in amniotic fluid and maternal urine samples taken during caesarean and authors concluded that several phthalates or their metabolites reach the human fetus; they also point out that further research is needed to elucidate fetal metabolism of phthalates and to evaluate the in utero phthalate exposure and the potential effects on fetal reproductive development [8].

The objective of this study is to measure the concentration levels of metabolites of four different phthalates, DEHP, DEP, DnBP and BBzP, namely MEHP, MEHHP, MEP, MnBP and MBzP (see Figure 1) in samples of amniotic fluid taken during the amniocentesis and to correlate them with those found in maternal urine collected in the same day, in order to investigate the mechanisms involved in fetal exposure. The study is within the priority areas defined by the Italian National Plan of prevention in protecting women and newborns, with the discouragement of risk behaviors like smoking and other exposures to chemicals caused by the life style, and predictive medicine, with early prevention of birth defects and disorders of sexual development in children, caused by in utero exposure to endocrine disruptors. 
DEP, di-ethylphthalate
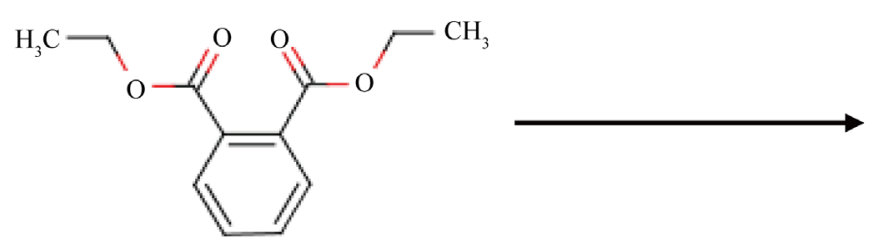

MEP, monoethylphthalate<smiles>CCOC(=O)c1ccccc1C(=O)O</smiles>

MEHP, mono-(2 ethylhexyl)-phthalate

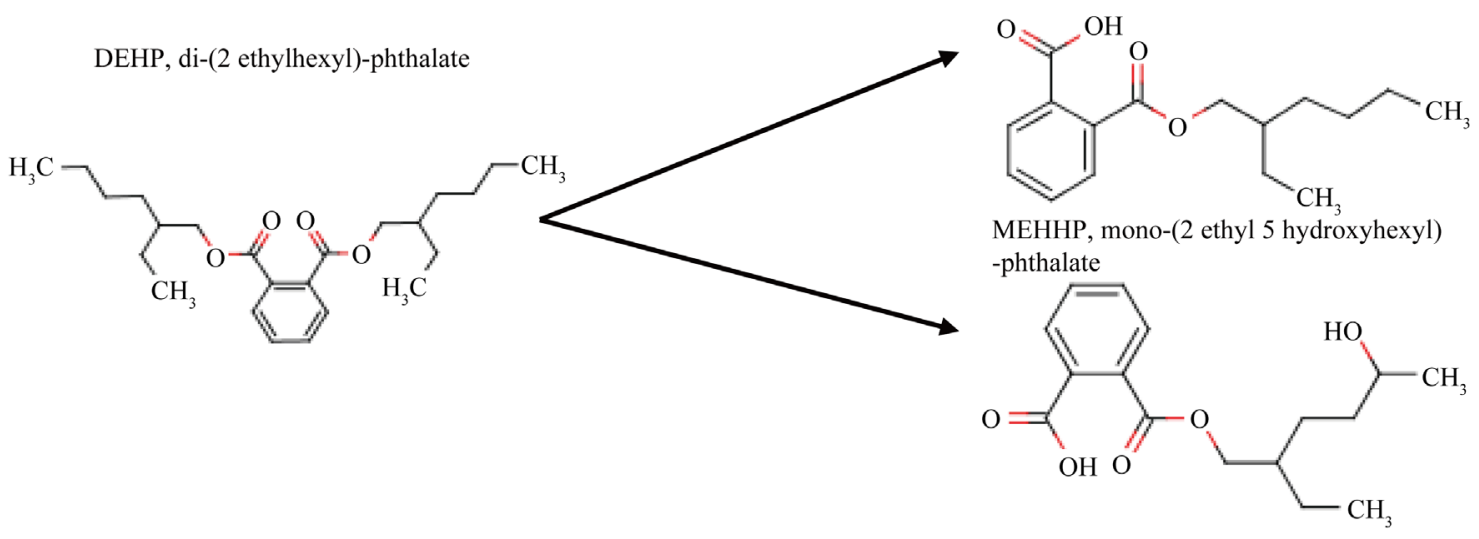

BBzP, n-butylbenzylphthalate

MBzP, mono-benzylphthalate<smiles>CCCCOC(=O)c1ccccc1C(=O)OCc1ccccc1</smiles>

DBP, di-n-butylphthalate

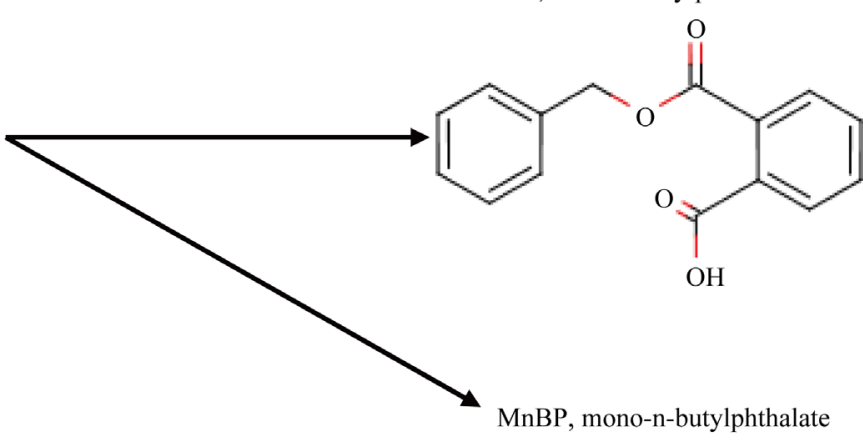<smiles>CCCCOC(=O)c1ccccc1C(=O)OCCCC</smiles>

Figure 1. Selected phthalates and their metabolites.

\section{Experimental Section}

\subsection{Chemicals and Supplies}

The analytical reference standards of mono-benzylphthalate (MBzP), mono(2-ethylhexyl) phthalate (MEHP), mono(2-ethyl-5-hydroxyhexyl) phthalate (MEHHP), mono butyl phthalate (MnBP) and mono-ethylphthalate 
(MEP) were purchased from Cambridge Isotope (Andover USA). The deuterium labelled internal standard ${ }^{13} \mathrm{C}-4$ Mono-benzylphthalate (MBzP- ${ }^{13} \mathrm{C}$ ) and ${ }^{13} \mathrm{C}-4$ Mono-ethylphthalate (MEP- $\left.{ }^{13} \mathrm{C}\right)$ were obtained from Cambridge Isotope (Andover USA). $\beta$-glucuronidase $E$. coli k-12 enzyme by Roche (Mannheim Germany). Glacial acetic acid (100\% Merck, Darmstadt, Germany) was used for preparing the mobile phase and for SPE, with purified water from a Milli-Q Plus system (Millipore, Milford, MA, USA). Methanol for SPE was supplied by J. T. Baker (Deventer, Holland). Acetonitrile by Romil Ups (Cambridge GB). OASIS HBL (6 cc, $200 \mathrm{mg}$ ) for SPE were supplied by Waters (Massachusetts Ireland), and the SPE vacuum manifold by Waters (Milford, MA, USA). Anotop $10 \mathrm{LC}$ syringe filter devices $(0.2 \mu \mathrm{m}$ pore size, $10 \mathrm{~mm}$ diameter) were purchased from Whatman Inc. (Maidstone, UK). Phenomenex Synergi Polar-4u RP C-18 column $(150 \times 4.6 \mathrm{~mm}, 4 \mu \mathrm{m}$ of particle size) was supplied by Chemtek Analytical s.r.l. (Bologna, Italy) and used throughout the study.

\subsection{Study Population}

The amniotic fluid samples were donated by pregnant women undergoing routine amniocentesis, generally carried out at 16 - 17 weeks of gestation and the first morning urine sample was collected on the same day scheduled for the test.

We did not select any particular group of women, but we used only amniotic fluid samples of those who accepted to provide a urine sample, for which we asked informed consent during the course of a preliminary consultation. As our study was considered an observational study on the basis of the definitions of the European Directive 2001/20/EC, therefore the approval of an Ethic Committee was not requested.

\subsection{Preparation of Urine Samples}

Urine samples were collected in sterile polypropylene containers and stored at $-20^{\circ} \mathrm{C}$ until analysis.

Samples have been tested both with and without enzymatic hydrolysis. The analytical method used to determine the metabolites after enzymatic hydrolysis was validated and described elsewhere [18]. Briefly, each sample was incubated with $\beta$-glucuronidase from $E$. coli k-12 enzyme at $37^{\circ} \mathrm{C}$, then acidified and ${ }^{13} \mathrm{C}$ labelled internal standards dissolved in methanol were added $\left({ }^{13} \mathrm{C}-4\right.$ Mono-benzylphthalate for analysis of MBzP, MEHHP, MEHP, MnBP, and ${ }^{13} \mathrm{C}-4$ Mono-ethylphthalate for analysis of MEP). Solid phase extraction (SPE) sample purification was then performed on OASIS cartridges, the eluate was filtered on $0.2 \mu \mathrm{m}$ syringe filter, and $20 \mu \mathrm{L}$ were injected (filling the injection loop volume) into the HPLC-MS/MS system API 4000 for quantitative analysis. Each sample was also retested without the incubation with $\beta$-glucuronidase, using the same procedure. The concentration of each metabolite in the urine expressed in $\mu \mathrm{g} / \mathrm{l}$ was normalized by dividing it by the urinary creatinine concentration, determined with alkaline picrate at a wavelength of $490 \mathrm{~nm}$, and expressed also as $\mu \mathrm{g} / \mathrm{g}$ creatinine [19].

\subsection{Preparation of Amniotic Fluid Samples}

Samples of amniotic fluid were taken during routine amniocentesis and subjected to centrifugation at $1500 \mathrm{~g} / \mathrm{min}$. A small volume of the non-cellular supernatant decanted is immediately frozen at $-25^{\circ} \mathrm{C}$, where it is stored until the birth of the child, and after which it is discarded or made available for experiments.

The analytical method used for the urine samples was slightly modified and used for the analysis of the amniotic fluid samples: $0.5 \mathrm{ml}$ of amniotic fluid were filtered and added with an equal volume of IS mixture in methanol, then $20 \mu \mathrm{L}$ were injected into the HPLC-MS/MS system, without performing the SPE step, in order to determine the concentration of the same five metabolites found in the urine samples. The results were expressed in $\mu \mathrm{g} / \mathrm{l}$.

\subsection{HPLC-MS/MS Analysis}

The HPLC analysis of all samples and calibration standard was performed on a Series 200LC quaternary pump (Perkin Elmer, Norwalk, CT, USA) using a $150 \times 4.6 \mathrm{~mm}, 4 \mu \mathrm{m}$ of particle size Synergi Polar-4 $\mu$ RP C-18 analytical column. The mobile phase was a linear gradient starting with $30 \%$ of acetonitrile and $70 \%$ of acetic acid $0.5 \%(\mathrm{v} / \mathrm{v})$ in water and reaching $90 \%$ of acetonitrile in 8 minutes at a flow rate of $1.0 \mathrm{~mL} / \mathrm{min}$. Retention times were $4.56 \mathrm{~min}$ for MEP, $5.41 \mathrm{~min}$ for MEHP, $5.76 \mathrm{~min}$ for MnBP, $6.10 \mathrm{~min}$ for MBzP and $7.27 \mathrm{~min}$ for MEHHP: total run time was 10 min. The detector was a AB Sciex API 4000, triple quadrupole mass spectrometer, fitted with a Turbo Ion Spray (TIS) probe working in the negative ion, multiple reaction monitoring (MRM) 
mode.

The following $\mathrm{m} / \mathrm{z}$ ion combinations (precursor $\rightarrow$ product) were monitored: $\mathrm{m} / \mathrm{z}-255 \rightarrow-183$ for $\mathrm{MBzP}, \mathrm{m} / \mathrm{z}$ $-293 \rightarrow-120.9$ for MEHHP, $\mathrm{m} / \mathrm{z}-277.2 \rightarrow-134.1$ for MEHP, $\mathrm{m} / \mathrm{z}-221.1 \rightarrow-120.9$ for MnBP and $\mathrm{m} / \mathrm{z}$ $-193.2 \rightarrow-120.9$ for MEP $m / z-257.0 \rightarrow-185.0$ for MBzP- ${ }^{13} \mathrm{C}$ and $m / z-195.2 \rightarrow-122.9$ for MEP $-{ }^{13} \mathrm{C}$. The concentrations were determined using a calibration curve obtained by analysis of standard solutions of the pure compounds and internal standards in a concentration range from 0 to $50 \mu \mathrm{g} / \mathrm{L}$ for the amniotic fluids and from 0 to $500 \mu \mathrm{g} / \mathrm{L}$ for the urine samples.

\section{Results and Discussion}

\subsection{Performances of Analytical Method on Amniotic Fluids}

The analytical method is able to separate and quantitate the five analytes in amniotic fluid within 10 minutes. For each analyte, calibration curves were constructed by linear regression analysis of the analyte-to-IS area ratio versus the known concentration of analytes injected $\left(r^{2}=0.998\right)$. Blanks intended as amniotic fluids free of phthalate metabolites cannot exist as phthalates are ubiquitous pollutants, but as phthalate metabolites and not phthalates are measured, exogenous contamination is not possible. Therefore the "blank samples" are the zero points of the calibration curve, and the presence of results below the LOD proves the absence of contamination of the laboratory procedure. Limits of Detection and Limits of Quantitation, reported in Table 1, indicate that the signal to noise ratio is higher in amniotic fluid, a less complex matrix than urine, as these values are lower than those reported for the urine in the literature [18].

\subsection{Biomonitoring Results}

The average results obtained on 70 urine samples of pregnant volunteers using the analytical method with the enzymatic hydrolysis, expressed both in $\mu \mathrm{g} / \mathrm{l}$ and in $\mu \mathrm{g} / \mathrm{g}$ of creatinine are shown in Table 2.

These results can be compared with those obtained in a study that examined of 157 healthy volunteers, including 83 women, reported in Table 3 [18].

The last column shows, for each metabolite, the number of pregnant women of this study having a urinary concentration greater than the upper limit of the confidence interval (CI) of $95 \%$ of the group of women in the

\begin{tabular}{ccc|}
\hline \multicolumn{3}{l}{ Table 1. Limits of detection and quantitation. } \\
\hline Metabolite & LOD & LOQ \\
\hline & $\mu \mathrm{g} / \mathrm{L}$ & $\mu \mathrm{g} / \mathrm{L}$ \\
\hline MnBP & 0.20 & 0.40 \\
MEP & 0.05 & 0.10 \\
MBzP & 0.05 & 0.10 \\
MEHP & 0.07 & 0.20 \\
MEHHP & 0.02 & 0.10 \\
\hline
\end{tabular}

Table 2. Results obtained on urine samples from 70 pregnant women.

\begin{tabular}{|c|c|c|c|c|c|c|c|c|c|c|}
\hline Urine & MnBP & MEP & MBzP & МЕНР & МЕННР & MnBP & MEP & MBzP & МЕНР & МЕНHР \\
\hline & & & $\mu \mathrm{g} / \mathrm{L}$ & & & \multicolumn{5}{|c|}{$\mu \mathrm{g} / \mathrm{g}$ of creatinine } \\
\hline Mean & 29.87 & 71.24 & 3.09 & 4.08 & 16.18 & 45.20 & 99.11 & 3.88 & 5.57 & 22.34 \\
\hline Std. Dev. & 23.91 & 104.75 & 3.43 & 7.44 & 21.75 & 59.42 & 144.63 & 4.65 & 9.93 & 26.33 \\
\hline Median & 24.20 & 37.85 & 1.76 & 1.06 & 9.16 & 32.66 & 55.48 & 2.25 & 1.59 & 12.90 \\
\hline Min & 3.13 & 3.65 & 1.20 & 0.45 & 0.78 & 6.51 & 7.59 & 1.31 & 0.11 & 0.76 \\
\hline Max & 136.50 & 748.00 & 12.90 & 41.10 & 156.00 & 472.63 & 1022.19 & 22.89 & 42.59 & 161.66 \\
\hline $\mathbf{N}>\mathbf{L O D}$ & 69 & 68 & 59 & 51 & 69 & 69 & 68 & 59 & 51 & 69 \\
\hline
\end{tabular}


Table 3. Urinary metabolites of phthalates considered expressed in $\mu \mathrm{g} / \mathrm{g}$ creatinine in pregnant and non pregnant women.

\begin{tabular}{cccc}
\hline Volunteer status & \multicolumn{2}{c}{ 83 Non-pregnant } & 70 Pregnant \\
\hline Metabolite & Median & $\mathbf{9 5 \% ~ C I ~}$ & Number with value $>$ CI (\%) \\
\hline MnBP & 26.70 & $8.17-28.43$ & $\mathbf{3 6}(\mathbf{5 1 . 4 )}$ \\
MEP & 65.80 & $3.63-149.51$ & $\mathbf{1 2}(\mathbf{1 7 . 1 )}$ \\
MBzP & 14.34 & $2.94-17.68$ & $\mathbf{4 ( 5 . 7 )}$ \\
MEHP & 3.03 & $1.85-4.89$ & $\mathbf{1 5}(\mathbf{2 1 . 4 )}$ \\
MEHHP & 14.29 & $9.45-22.19$ & $\mathbf{1 7}(\mathbf{2 4 . 3 )}$ \\
\hline
\end{tabular}

cited study (reference values), that is up to $50 \%$ of the total in the case of MnBP.

The results obtained for the concentration of phthalate metabolites in amniotic fluid of the volunteers are given in Table 4.

The results confirmed that the concentrations of phthalate monoesters in amniotic fluid are lower than those found in maternal urine and that the metabolites having a higher concentration in the amniotic fluid are MnBP and MEHP. The results are consistent with literature data reporting of similar analyses [8] [9].

The amniotic fluids have been tested both with and without performing the enzymatic hydrolysis and the free percentage (non-conjugated/total) is reported in Table 4, together with the number of valid pairs of data on which it was calculated. The levels of MnBP, MEP, MEHP and MEHHP in the amniotic fluid do not increase significantly with the enzymatic hydrolysis, indicating that they are present mainly in the free form. The result obtained for MBzP is not consistent with those of the other metabolites, but due to the very low concentrations detected it is affected by a larger uncertainty.

The correlation between the concentration of the five metabolites in amniotic fluids and maternal urine was then examined. Analyzing the data with the Shapiro-Wilk test these are not normally distributed $(p<0.05)$ and therefore the Spearman's Rho test it was used to examine the non-parametric correlation between the individual values obtained in maternal urine and amniotic fluids, both expressed in $\mu \mathrm{g} / \mathrm{l}$, finding no statistical significance $(\mathrm{p}>0.05)$.

However, as the urinary metabolites were determined after enzymatic hydrolysis of the form conjugated with glucuronic acid while in the amniotic fluid they are mainly in the free form, the relationship between the free forms in the two matrices was examined.

The metabolites concentrations found without enzymatic hydrolysis in the urine samples are shown in Table 5 , together with the percentage of the free form with respect to the total and the number of valid data on which it was calculated.

The results confirm that, as reported in the literature, only the MEP is present in human urine in significant concentration in the non-glucuronidated form [20].

Also in this case, being the data distribution not-normal, the non-parametric Spearman's Rho test was used to examine the correlation between the individual values obtained for maternal urine and amniotic fluid: significant results were found for MnBP $(r=0.48, p<0.05)$ and MEP $(r=0.54, p<0.05)$ and MEHP $(r=0.98, p<0.01)$, indicating that the concentration of the free metabolites is a measure of fetal exposure to the corresponding phthalates.

\section{Conclusions}

This is one of the few published studies investigating the relationship between concentrations of phthalate metabolites in amniotic fluid and urine samples from pregnant women. Almost all of the amniotic fluid samples tested contain measurable concentrations of the metabolites of the considered phthalates, being MnBP and MEHP the more abundant, although significantly lower than the values found in the maternal urine, confirming fetal exposure to these compounds.

From the results it seems that the concentration of the metabolites in the amniotic fluid does not increase with the enzymatic hydrolysis, indicating that they are present mainly in a non-glucuronidated form, and suggesting that conjugated metabolites do not cross the placental barrier, probably due to the larger size of the molecule.

Testing the concentrations without enzymatic hydrolysis, statistically significant correlations were found between the free forms found in the amniotic fluid and maternal urine for MEP, MnBP and MEHP: These results 
Table 4. Results obtained on samples of amniotic fluid of 70 pregnant women.

\begin{tabular}{|c|c|c|c|c|c|}
\hline & MnBP & MEP & MBzP & МEHP & МЕНHР \\
\hline & \multicolumn{5}{|c|}{$\mu \mathrm{g} / 1$} \\
\hline Mean & 3.53 & 0.70 & 0.16 & 1.47 & 0.25 \\
\hline Std. Dev. & 2.33 & 0.76 & 0.12 & 5.03 & 0.20 \\
\hline Median & 3.18 & 0.46 & 0.14 & 0.67 & 0.41 \\
\hline Min & $<\mathrm{LOD}$ & $<\mathrm{LOD}$ & $<\mathrm{LOD}$ & $<\mathrm{LOD}$ & $<$ LOD \\
\hline Max & 9.15 & 3.65 & 0.50 & 50.20 & 0.48 \\
\hline $\mathbf{N}>$ LOD & 58 & 48 & 55 & 41 & 40 \\
\hline$\%$ free & 98 & 81 & 39 & 107 & 119 \\
\hline Pairs of data (N) & 49 & 24 & 40 & 41 & 32 \\
\hline
\end{tabular}

Table 5. Free concentrations of phthalate metabolites in maternal urine.

\begin{tabular}{|c|c|c|c|c|}
\hline \multirow{2}{*}{ Free Metabolite } & \multicolumn{4}{|c|}{ Urine $(\mu \mathrm{g} / \mathrm{L})$} \\
\hline & Mean (SD) & Median & $\mathrm{N}<\mathrm{LOD}$ & $\%$ Free \\
\hline MnBP & $1.65(2.2)$ & 0.98 & $12 / 70$ & 4.0 \\
\hline MEP & 39.94 (45.71) & 28.75 & $3 / 70$ & 76.35 \\
\hline MBzP & $0.06(0.08)$ & 0.05 & $36 / 70$ & 2.8 \\
\hline МЕНР & $0.53(0.8)$ & 0.05 & $36 / 70$ & 4.7 \\
\hline МЕНHР & $0.44(0.3)$ & 0.44 & $0 / 70$ & 4.8 \\
\hline
\end{tabular}

indicate that the concentration of free metabolites in maternal urine can be considered a measure of the fetal exposure.

Due to the very low concentrations measured in the amniotic fluids, these considerations are based on a number of valid data smaller than 70, and therefore they need to be confirmed on larger numbers.

The results obtained on 70 pregnant volunteers compared with the reference values of the same metabolites in women from a general population study showed that pregnant women have higher urinary concentration of phthalate metabolites; therefore it seems important to inform pregnant women about the negative effects of phthalate exposure on the newborns' health, and about their possible sources, in order to reduce the use of phthalates containing products during pregnancy; it would be also desirable to limit the concentration of phthalates in products, specially cosmetics, intended for pregnant women.

\section{References}

[1] Angerer, J., Ewers, U. and Wilhelm, M. (2007) Human Biomonitoring: State of the Art. International Journal of Hygiene and Environmental Health, 210, 201-228. http://dx.doi.org/10.1016/j.ijheh.2007.01.024

[2] Barr, D.B., Bishop, A. and Needham, L.L. (2007) Concentrations of Xenobiotic Chemicals in the Maternal-Fetal Unit. Reproductive Toxicology, 23, 260-266. http://dx.doi.org/10.1016/j.reprotox.2007.03.003

[3] Foster, W.G., Hughes, C.L., Chan, S. and Platt, L. (2002) Human Developmental Exposure to Endocrine Active Compounds. Environmental Toxicology and Pharmacology, 12, 75-81. http://dx.doi.org/10.1016/S1382-6689(02)00025-X

[4] Foster, W.G., Chan, S., Platt, L. and Hughes, C.L. (2000) Detection of Endocrine Disrupting Chemicals in Samples of Second Trimester Human Amniotic Fluid. The Journal of Clinical Endocrinology and Metabolism, 85, 2954-2957. http://dx.doi.org/10.1210/jcem.85.8.6850

[5] Luzardo, O.P., Mahtani, V., Troyano, J.M., Alvarez de la Rosa, M. and Padilla-Perez, A.I. (2009) Determinants of Organochlorine Levels Detectable in the Amniotic Fluid of Women from Tenerife Island (Canary Islands, Spain). Environmental Research, 109, 607-613. http://dx.doi.org/10.1016/j.envres.2009.03.008

[6] Engel, S.M., Levy, B., Liu, Z., Kaplan, D. and Wolff, M.S. (2006) Xenobiotic Phenols in Early Pregnancy Amniotic Fluid. Reproductive Toxicology, 21, 110-112. http://dx.doi.org/10.1016/j.reprotox.2005.07.007

[7] Silva, M.J., Reidy, J.A., Herbert, A.R., Preau Jr., J.L. and Needham, L.L. (2004) Detection of Phthalate Metabolites in Human Amniotic Fluid. Bulletin of Environmental Contamination and Toxicology, 72, 1226-1231. 
http://dx.doi.org/10.1007/s00128-004-0374-4

[8] Wittassek, M., Angerer, J., Koloss-Gehring, M., Schafer, S.D. and Klockenbusch, W. (2009) Fetal Exposure to Phthalates-A Pilot Study. International Journal of Hygiene and Environmental Health, 212, 492-498. http://dx.doi.org/10.1016/j.ijheh.2009.04.001

[9] Huang, P.C., Kuo, P.L., Chou, Y.Y., Lin, S.J. and Lee, C.C. (2009) Association between Prenatal Exposure to Phthalates and the Health of Newborns. Environment International, 35, 14-20. http://dx.doi.org/10.1016/j.envint.2008.05.012

[10] Swan, S.H., Liu, F., Hines, M., Kruse, R.L. and Wang, C. (2009) Prenatal Phthalate Exposure and Reduced Masculine Play in Boys. International Journal of Andrology, 32, 1-9.

[11] Dobek, D., Karmowski, A., Sobiech, K.A., Terpiłowski, L. and Miś-Michałek, M. (1998) Average Quantitative Concentration of Cotinine within the System Pregnant Woman-Baby. Archivum Immunologiae et Therapia Experimentalis (Warsz), 46, 59-61.

[12] Swan, S.H. (2008) Environmental Phthalate Exposure in Relation to Reproductive Outcomes and Other Health Endpoints in Humans. Environmental Research, 108, 177-184. http://dx.doi.org/10.1016/j.envres.2008.08.007

[13] Sathyanarayana, S., Karr, C.J., Lozano, P., Brown, E. and Calafat, A.M. (2008) Baby Care Products: Possible Sources of Infant Phthalate Exposure. Pediatrics, 121, 260-268. http://dx.doi.org/10.1542/peds.2006-3766

[14] Hauser, R. and Calafat, A. (2005) Phthalates and Human Health. Occupational and Environmental Medicine, 62, 806818. http://dx.doi.org/10.1136/oem.2004.017590

[15] Martinez-Arguelles, D.B., Campioli, E., Culty, M., Zirkin, B.R. and Papadopoulos, V. (2013) Fetal Origin of Endocrine Dysfunction in the Adult: The Phthalate Model. Journal of Steroid Biochemistry, 137, 5-17. http://dx.doi.org/10.1016/j.jsbmb.2013.01.007

[16] Latini, G. (2005) Monitoring Phthalate Exposure in Humans. Clinica Chimica Acta, 361, 20-29. http://dx.doi.org/10.1016/i.cccn.2005.05.003

[17] Sathyanarayana, S., Calafat, A.M., Liu, F. and Swan, S.H. (2008) Maternal and Infant Urinary Phthalate Metabolite Concentrations: Are They Related? Environmental Research, 108, 413-418. http://dx.doi.org/10.1016/j.envres.2008.07.002

[18] Tranfo, G., Papaleo, B., Pigini, D., Corsetti, F. and Caporossi, L. (2013) Urinary Metabolite Concentrations of Phthalate Metabolites in Central Italy Healthy Volunteers Determined by a Validated HPLC/MS/MS Analytical Method. International Journal of Hygiene and Environmental Health, 216, 481-485. http://dx.doi.org/10.1016/j.ijheh.2012.11.003

[19] Jaffè, M. (1886) Uber den Niederschlang welchen pikrinsaure in normalen Harn erzeigt und über eine neue Reaction des Kreatinins. Hoppe-Seyler's Zeitschrift fur physiologische Chemie, 10, 391-400.

[20] Silva, M.J., Barr, D.B., Reidy, J.A., Kato, K. and Malek, N.A. (2003) Glucuronidation Patterns of Common Urinary and Serum Monoester Phthalate Metabolites. Archives of Toxicology, 77, 561-567. http://dx.doi.org/10.1007/s00204-003-0486-3 
Scientific Research Publishing (SCIRP) is one of the largest Open Access journal publishers. It is currently publishing more than 200 open access, online, peer-reviewed journals covering a wide range of academic disciplines. SCIRP serves the worldwide academic communities and contributes to the progress and application of science with its publication.

Other selected journals from SCIRP are listed as below. Submit your manuscript to us via either submit@scirp.org or Online Submission Portal.
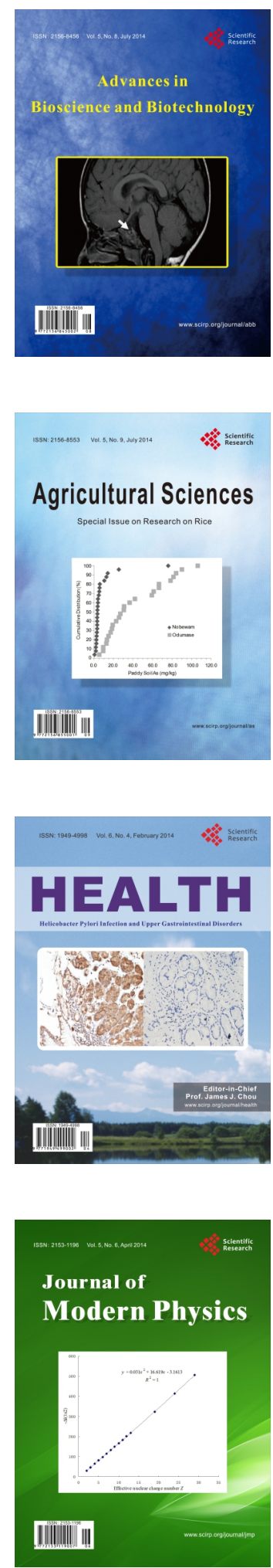
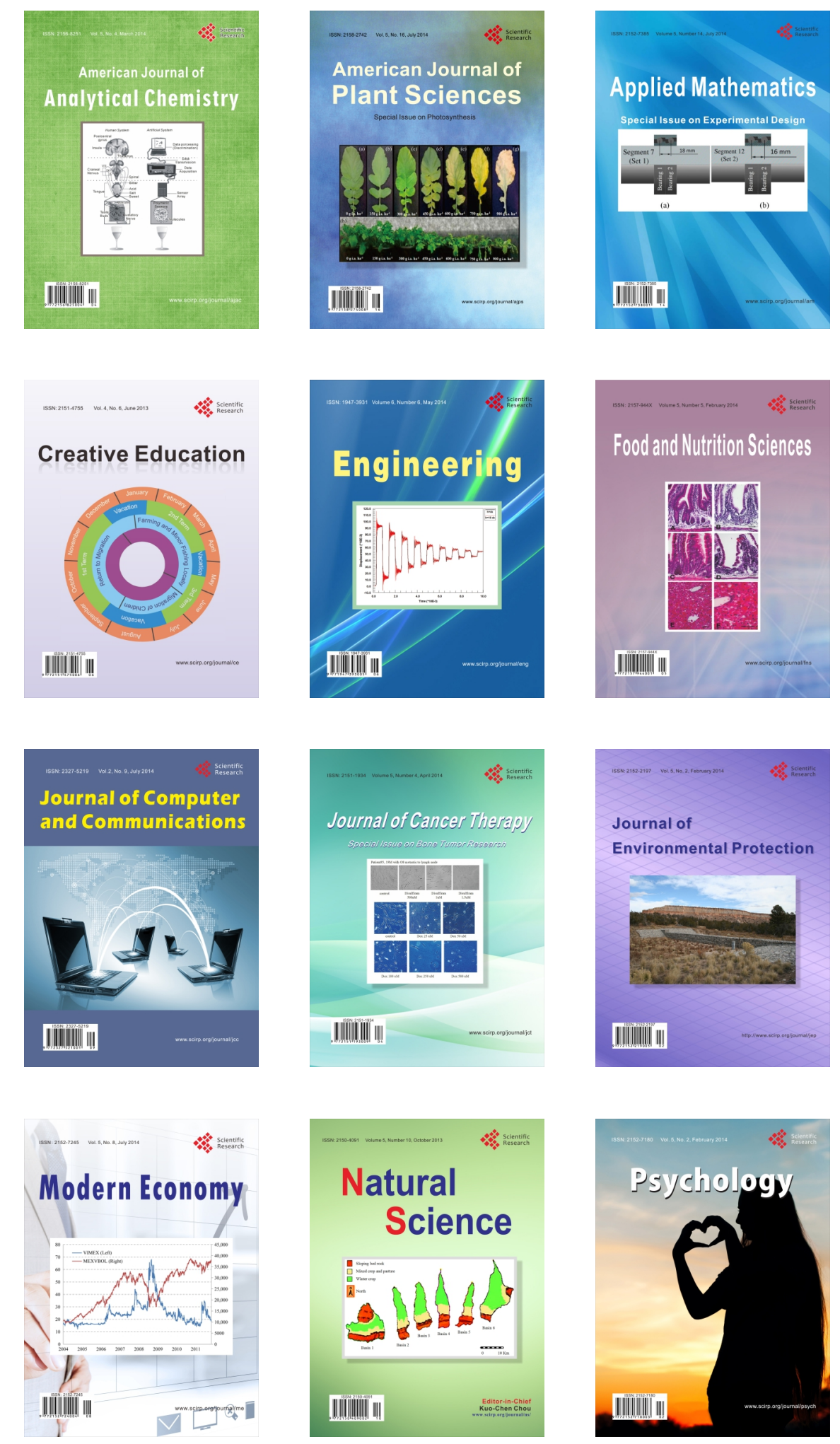